RESEARCH ETHICS

\title{
What is the role of the research ethics committee? Paternalism, inducements, and harm in research ethics
}

\author{
E Garrard, A Dawson
}

$J$ Med Ethics 2005;31:419-423. doi: 10.1136/jme.2004.010447

In a recent paper Edwards, Kirchin, and Huxtable have argued that research ethics committees (RECs) are often wrongfully paternalistic in their approach to medical research. They argue that it should be left to competent potential research subjects to make judgments about the acceptability of harms and benefits relating to research, and that this is not a legitimate role for any REC. They allow an exception to their overall antipaternalism, however, in that they think RECs should have the power to prohibit the use of financial inducements to recruit research subjects into trials. In this paper it is argued that these claims are unjustified and implausible. A sketch is provided of an alternative model of the role of the REC as an expert body making judgments about the acceptability of research proposals through a consensual weighing of different moral considerations.

See end of article for authors' affiliations

\section{Correspondence to:} Eve Garrard, Centre for Professional Ethics, Keele Hall, Keele University, Staffs, ST5 5BG, UK; e.garrard@keele.ac.uk

Received

27 September 2004 Accepted for publication 29 September 2004
O ver the last quarter century, the practice of medical research has increasingly been regulated by research ethics committees (RECs). ${ }^{12}$ There is not, however, uniform agreement on what their role is, so the question arises: what exactly are RECs for? Usually there are two different answers to this question: on the one hand, they are seen as primarily there to protect the research subject from harm; on the other hand, it is thought that their principal role is to ensure that nothing happens to the research subject without her valid consent. ${ }^{\mathrm{i}}$

Some people, of course, think the role of the REC should encompass both these aims, but this construal of the purpose of RECs will obviously raise issues about prioritisation when the two aims come into conflict, as they can easily do.

In their paper, 'Research ethics committees and paternalism', Edwards, Kirchin, and Huxtable argue for a strongly consent oriented view of the role of the REC. ${ }^{3}$ They argue that although non-competent research subjects may be in need of protection by the REC, the case of competent subjects does not warrant this paternalistic approach. In their view, the role of the REC vis à vis competent subjects should be, within the limits set by public policy, that subjects give a genuinely valid consent to participation in the research in question. This means that a research ethics committee's obligations might end, once they have required a researcher to include an accurate statement about risks in the patient information sheet. (Rather oddly, Edwards et al suggest that where the REC thinks the research is unnecessarily risky, a statement to this effect should also appear on the sheet.). The principal reason that they offer for taking this strongly antipaternalistic line is that competent recruits are in the best available position to say what risks are reasonable for them, certainly in a better position than the REC is. This argument could be interpreted as primarily a beneficence based one; but there is some internal evidence in the paper to suggest that a more general concern for, and privileging of, respect for autonomy is what is driving the authors' adoption of this view of the role of the REC: "clearly we have emphasised the importance of respect for autonomy" (Edwards et al, ${ }^{3}$ p 90).

However, Edwards et al do allow, in fact they insist on, one exception to their overall antipaternalism, and that is with respect to the offer of money to research subjects. They think RECs should at least have the discretionary power to prohibit the use of financial inducements to recruit research subjects into trials; and the reason they offer for this is that such inducements are (according to them) psychologically manipulative and potentially exploitative. In cases where the REC thinks financial inducements are being offered with the aim of manipulating and exploiting potential subjects, it is legitimate, so Edwards et al argue, for the REC to adopt a protective and paternalistic stance in order to ensure that research subjects are not harmed in this way.

There are serious difficulties with Edwards et al's argument, both the overall antipaternalism stance, and the specific prohibition on the offer of inducements to research subjects. Not only are each of these positions insufficiently grounded in this paper, they are also (so we will argue) incompatible with each other. We will treat the problems with antipaternalism in section I, and in section II we will address the issue of inducements. Finally, in section III we will offer an alternative view of the role of RECs.

\section{Abbreviations: REC, research ethics committee}

'We deliberately refer to research subjects and not participants. This is because we believe that the term "subjects" actually gives a closer approximation to what it is like to be a patient involved in a research project. In addition, the term "participant" is unclear since, technically, medical researchers are also research participants. 


\section{RECS AND PATERNALISM i. Paternalism}

Edwards et al claim that it should not be a research ethic committee's role to act paternalistically towards patients by "rejecting research that poses risk to people who are competent to decide for themselves" except where patients are "vulnerable" (Edwards et al, ${ }^{3}$ p 88). By "vulnerable" patients they seem to have two categories in mind: the incompetent, and those whose autonomy is undermined by financial incentives. We will return to the issue of vulnerability in our discussion of inducements in section II; in this section we concentrate on the claim about paternalism and competent research participants.

Edwards et al define "paternalism" in terms of what is commonly called "strong paternalism" - that is, overriding a person's autonomy for his or her own good. They refer to Beauchamp and Childress in support of their view. ${ }^{4}$ It should be noted, however, that Beauchamp and Childress have a more nuanced account of paternalism, and explicitly hold that autonomy can be overridden by other moral considerations in at least some situations. Presumably the reason for the authors' ultimately hostile view of paternalism is that they believe the importance of respecting an individual's autonomous decision making takes priority over other moral considerations-for example, beneficence and non-maleficence. They seem to believe that these factors cannot be used to justify paternalism in relation to competent research participants and that therefore paternalism on such grounds is morally wrong. They do not, however, offer any arguments for prioritising respect for autonomy in this way, and nothing in their discussion of it rules out the possibility of construing its importance in a more nuanced, less absolutist, way. So, for example, we could hold that autonomy is an important value, which in general ought to be promoted, but that our moral deliberations do (and should) involve other moral considerations too, particularly ones to do with harm and benefit.

On this kind of understanding of the interplay of different moral considerations, it becomes possible to think of paternalism as something that may or may not be justifiable, depending upon the particular situation under discussion, and the particular moral considerations that obtain in it-for example, one very good reason to be paternalistic is to prevent serious harm to people. That is, at least some actions performed with the aim of preventing harm may count as paternalistic actions, but may none the less be justifiable. A research ethics committee might, for example, choose to prohibit researchers from injecting themselves with a new preventive vaccine for HIV because it is held that the risk of harm from the live vaccine's constituents was too great. ${ }^{5}$ Edwards et al simply assert the primacy of respect for autonomy as a moral consideration, but nothing in the argument they actually provide rules out the possibility that harm considerations should sometimes take priority over autonomy considerations. Hence nothing in their argument rules out the possibility that in at least some situations RECs are justified in blocking research subjects' involvement in research even if those subjects are competent, fully informed, and autonomous. (And as we shall see in section II, Edwards et al do themselves accept this in certain circumstances.)

\section{ii. The main claim}

In this section we outline what we take to be Edwards et al's reasons for holding their view about the unjustifiability of paternalism in the research context, and suggest some problems for their position. The main justification which they explicitly provide is the claim that "individual recruits are in the best position to say what risks are reasonable for them" (Edwards et al, ${ }^{3}$ p 88). What exactly do they mean by this claim, however, and is it true?
The first thing to say is that appeals to "reasonableness" are notoriously vague, here as elsewhere. Do the authors mean "acceptable", "rational", "all things considered, most relevant"? Is this a claim about judging "best interests", or something else? Although it is not clear exactly what Edwards et al intend by using such a term, presumably this is at least partly an epistemic claim, which then, in turn, is supposed to entail a moral claim to authoritative decision making about an individual's own situation. Assuming this to be what Edwards et al mean, then as an epistemic claim it undoubtedly has some truth. Generally it is indeed the case that we will be the best judge of what considerations are most relevant to each of us, as no one knows our individual situation better than ourselves. Such epistemic authority has, however, some clear limits: in specific situations there might be a variety of reasons why an individual would not be best placed to make such judgments. An individual's judgment might be clouded by such things as irrational fears, an overoptimistic view of research, or a misplaced sense of altruism. In these cases, the individual's epistemic authority is in doubt. If this is correct, then we have good grounds also to doubt the presence of the moral authority that supposedly follows from the epistemic claim. At best, all we can legitimately claim is that competent research participants have a distinctive, and sometimes authoritative, insight into their own situation and concerns, and that they should bring the considerations yielded by that insight to the fore when they make a judgment about whether they wish to participate in research.

As well as this point about the ways in which an individual's judgment may be clouded in particular situations, there is also a second and still stronger point that directly challenges the claim to participants' epistemic authority in relation to their own situation. Here the thought is that people who are external to the research, who are not participants in it, may be in a better position to judge risks relating to research than many participants themselves. In fact, this is one of the main tasks for any research ethics committee. And the reason that RECs might be regarded as better able to make these judgments is that they contain a range of expertise among their membership (including a lay perspective) that may, all things considered, give a better assessment of any risk of harm from the research. It can be argued that they are in fact much better placed than any individual to make exactly such an assessment, because of both the diversity and relevance of their expertise, and the nature of judgment formation through consensus. While such an approach will not be perfect, it may well be better than any given individual's. (Indeed, as we suggest later, this may provide some of the "authority" for RECs that Edwards et al feel is so problematic.) If, as they suggest, all that is required from RECs is to ensure that the information given to potential research subjects is comprehensible, then perhaps we would just need a solitary research information officer to sign off the patient information sheet as being suitably transparent. Why have a REC at all?

This point becomes even stronger when we explore the scope of Edwards et al's claims. Most of their discussion is focused on phase 1 trials (hence their outline of the Gelsinger and Roche cases). Indeed, their argument might be most plausible in relation to such trials, where recruits are generally healthy and competent volunteers; but they do seem to want to extend their argument to other types of trials as well (they invoke research involving those with HIV and AIDS, and refer to their argument as applying to "therapeutic research" (Edwards et al, ${ }^{3} \mathrm{p} \mathrm{88}$ ). If they mean, as it appears they do, to generalise their argument across all research, it is not clear that it will work in the same way in relation to those participants who are suffering from illness. This is because 
although illness may not be so severe that it threatens an individual's competence, it might still influence the way that patients reason, to the extent that they are more likely to fail any test of epistemic authority about what risks are "reasonable" for them. It seems, for example, plausible to think that competent sick individuals will be more willing than competent healthy ones to participate in research. In our view, part of the legitimate role of the REC is to make judgments about risk on behalf of patients, taking into account the fact that the patients may be ill. A research ethics committee may want to turn down some proposed piece of research on the grounds that the risk of harm to the participants is too great. This would indeed be paternalistic, but such paternalism may well be justified, since the judgment about the risk of harm may be correct, and more evident to the REC than to the potential research subject.

Thirdly, Edwards et al's main claim can be challenged on the basis of yet another concern about leaving competent research participants to make up their own minds about whether to participate on the basis of full information about the research. This objection will appeal to the existing published psychological evidence about the problems research subjects have in comprehending and assessing information within the context of research trials. This research suggests that many subjects find it difficult to judge relevant information in the appropriate way, to the extent that we might hold that we might worry about their ability to give an informed consent. Perhaps the best example of this phenomenon is patients' lack of comprehension of the concept of "randomisation" within the context of a randomised controlled trial. ${ }^{6-8}$ This evidence is consistent with general psychological evidence in relation to the problems many have with information processing. ${ }^{910}$ Such evidence should give pause to anyone attracted to Edwards et al's position. (It should be noted that these research subjects were held to be competent and in many cases were held to have given an informed consent, so we should not assume that lack of comprehension by itself undermines competence). The concern here is that this evidence presents a good reason not to leave decision making entirely to the prospective participants themselves. Indeed, such material suggests it might be highly appropriate to have another body such as a research ethics committee making a judgment about risks of harm as a means of protecting potential subjects from inappropriate judgments that they themselves may make about participating in research. In other words, a research ethics committee's paternalism might be justified through an appeal to the potential risk of harm to research subjects (especially if they are also patients), even where they are competent and willing to participate in the research.

Edwards et al do make one concession to concerns about harm: they suggest that where a research ethics committee judges that proposed research is potentially harmful, the REC may insist that the researcher subjects all potential recruits to an independent psychological assessment to ensure they are capable of understanding the relevant risks. We find it hard to believe, however, that they can really be serious about this. It would have a highly detrimental impact upon research in health care as it would slow down research, significantly increase its cost, and almost certainly reduce recruitment to trials. Furthermore, their proposal, if enacted, would not even meet the objections discussed in the rest of this section, as we have in fact been talking only about competent patients. All that Edwards et al's proposal would do is isolate a non-competent subgroup within those generally considered competent by researchers. Our objections still stand.

\section{iii. Autonomy and other principles}

The previous section outlined a series of objections to what we take to be Edwards et al's main justificatory claim. We have argued, against this view, that there are good grounds to believe that in at least some cases a REC's paternalistic decision making about risk of harm may be justified. This is because it might be argued that if the potential harm is great enough, even competent potential participants should be protected from potentially disastrous autonomous choices. The justification for this view is based on an appeal to other moral considerations such as beneficence and non-maleficence, and the claim that such principles can over-rule the principle of autonomy in at least some cases. While it would be inappropriate to offer a full moral theory in defence of such a view in this paper, the idea behind this thought is the common and plausible view that such moral principles are only prima facie rather than absolute in nature. This means there is no justification for holding that the principle of respect for autonomy takes priority over the other principles in any way; its status is equal to that of other principles, and they are to be weighed against each other with outcomes which will differ in different situations. However, although no defence of the supposed priority of autonomy is given by the authors in their paper, they could, of course, offer one. Two possibilities spring to mind.

First is the idea that respect for autonomy might be justified by the consequences in terms of the degree of welfare or beneficence it brings about. Generally it is true that people are happier if they are able to make their own decisions. To deploy this argument, however, Edwards et al would have to demonstrate that this is indeed the case in the example of medical research. It is not clear, however, that this is so. At least some research participants may not want to be involved in decision making about such risks. They may expect and prefer a REC to make such judgments. Certainly if Edwards et al want to rely on such a welfare defence, then welfare produced through autonomy based considerations will clearly have to be weighed against welfare produced by other considerations; as a result, the authority or priority of autonomy will melt away.

A second, and stronger, suggestion would be that the primacy of respect for autonomy is justified by some putative right to bodily integrity and control, and that this right trumps other considerations. We take it that the authors do not support such a view. Certainly they do not offer any such support (and their views on exploitation seem to suggest otherwise). In any case, such a view is highly implausible. While most people can accept autonomy as an independent and important value, it is quite another thing to hold that it takes priority over all else, and there are many counterexamples-for example, the standard refusal of transplant teams to accept the donation of a second kidney-which indicate that we do not in practice endorse this privileged position for autonomy. So although it is possible to hold such a strongly libertarian view, it is not an intuitively attractive stance, nor is it widely endorsed; nor do Edwards et al provide us with arguments to support it. Lack of space precludes our giving a fuller critique of this view but see Holm. ${ }^{11}$ In the absence of any justification for holding autonomy to have the status of an overriding or trumping principle, we have better reason to regard autonomy as a prima facie moral principle, to be weighed against other moral considerations as appropriate. RECs, rightly, sometimes prioritise autonomy, and sometimes prioritise harm prevention. In fact, we find that Edwards et al themselves accept this view with regard to one aspect of research practice, namely the offering of financial inducements to participate in research. We now turn to consider this part of Edwards et al's argument. 


\section{RECS AND INDUCEMENTS}

As we have seen, Edwards et al think that RECs should generally protect only consent, rather than research subjects' interests. Although much of their paper is devoted to claiming that RECs should not be paternalistic, they allow one exception to this: RECs, they think, should prevent researchers from recruiting for their trials by offering financial inducements to competent research subjects. The reason they provide for making this exception is that inducements are (allegedly) exploitative when they are offered to those who are vulnerable to financial suggestion-for example, say Edwards et al, the poor.

There are two main problems with this claim.

\section{i. The problem of inconsistency}

The prohibition on offering inducements seems to be inconsistent with the assertion that "Judgements that involve balancing the value of research against the risks associated with it should be made primarily by the potential recruits themselves. A competent person would have to take into account all factors relevant to him or her" (Edwards et al, ${ }^{3}$ p 89) (their emphasis). Why would we suppose that this dictum, grounding as it does the overall claim of the paper that RECs should avoid paternalism, does not apply in the case of inducements? Surely one of the things competent persons do typically know better than others is how much they need a given sum of money, and what kind of risk they wish to run for it. So why in this area out of all others should we find paternalism being called for? What is needed here, to support the making of this exception, is a further argument showing why in the case of inducements research subjects no longer stand in the best position to judge the risks and benefits to, and for, themselves. No such argument is forthcoming.

It would not, of course, be enough to appeal to any harm which inducements are supposed to involve for research subjects. Since the general thrust of Edwards et al's argument has been that RECs should protect only consent, leaving subjects to decide for themselves what harms they are prepared to risk, some extra argument would still be needed to show that the putative harm resulting from inducements should be the subject of preventive paternalism.

\section{ii. The exploitation claim}

Leaving to one side the issue of inconsistency, there is a problem in seeing what it is that is supposed to justify the ban on inducements in research. Even if Edwards et al did think RECs should aim to protect research subjects' interests as well as their consent, why are inducements a candidate area for such protection-what harm to the research subject is avoided if inducements are banned? The argument given by Edwards et al seems to amount to the claim that inducements are manipulative and potentially exploitative. The offering of payment is described without qualification as a type of psychological manipulation, and we are then told that inducements should be prevented if "they have been offered so as to exploit those who are vulnerable to financial suggestion-for example the less well off" (Edwards et al, ${ }^{3}$ $\mathrm{p} 90$ ). The conditions in which inducements should be prohibited are further glossed as cases where "the money offered is primarily designed to manipulate, and further to exploit, those who cannot resist its lure".

Various difficulties arise for these claims. To take the final one first, if the worry about inducements is to do with exploitation then the focus on the motivations of the researchers in offering inducements is misplaced. The intention to exploit is neither necessary nor sufficient for the presence of exploitation, so if what is wrong with inducements is that they are exploitative, then we should not be focusing on researchers' motives, but rather on whether the conditions for exploitation are present in inducements to participate in research trials. ${ }^{\text {ii }}$

Secondly, Edwards et al's worry about exploitation seems to focus on the poor, because they are "vulnerable to financial suggestion". Presumably this means that they are prepared to alter their choices for the sake of the money that is offered. This is, however, hardly peculiar to the "less well off" - most people are prepared to alter many of their choices for the sake of money. Most people are not prepared to work regularly without payment, and most people are prepared to work if suitably paid. If being "vulnerable to financial suggestion" is what opens people to exploitation, then almost all of us are in this condition, the rich as well as the poor.

Perhaps what Edwards et al mean is that the less well off are likely to alter their choices for the amount of money which researchers could afford to offer as inducements, whereas more affluent people would not. That may well be true. This, however, cannot by itself show that what we have here is a case of exploitation, unless being prepared to alter your choices for the sake of a large sum of money is also a case of exploitation, in which case the high salaries typically offered to the affluent will also have to be regarded as exploitative. This, however, stretches the concept of exploitation to counterintuitive lengths. If, however, what we are really worried about is not so much exploitation as the possibility of harm to people's interests, then it is not clear why giving the competent poor the chance to decide whether to take risks for the sake of pay is overall harmful-after all, by definition they are more likely to need, and therefore benefit from, the money than the rich are. Also, in other areas of our lives we do allow, and even encourage, poor people to take risks for the sake of (among other things) money-we pay firefighters, oil rig workers, soldiers, and the police, and we do not regard this as so exploitative that it should be prohibited, even though the work in question is often very risky, and even though these workers are often drawn from less affluent backgrounds.

The final problem with the exploitation claim is Edwards et al's assertion that inducements amount to psychological manipulation. Again, if this means that inducements affect people's motivations, and hence their choices, that is true, but no more true for the case of medical research than for any other offer of cash, such as, for example, a "Reduced in the Sale" sign, which also affects people's choices. People do regularly take financial benefit into account when considering their reasons for action, and they are generally rational to do so. To regard this as manipulative and exploitative in the case of the poor, but not of the rich, is to treat the poor as really less competent, more in need of protective paternalism, than more affluent subjects. We do not, of course, wish to deny that the poor are more open to manipulation and exploitation than the rich. Of course they are, but not merely in virtue of being vulnerable to financial suggestion, as Edwards et al suggest. More than that is needed to show that financial inducements to participate in research are exploitative. (And if the authors are prepared to heroically bite the bullet and claim that all cases where money affects people's choices are cases of manipulation and exploitation, again we would have a counterintuitive stretching of the concept of exploitation. The main effect of this would be to weaken its proscriptive force-it would now cover too many cases, would come too cheap, for us to be sure that it is generally a bad thing.)

None of the above is meant to show, or could show, that inducements in research are desirable. There may well be

iiFor an excellent discussion of different conceptions of exploitation and related ethical issues see Bodies for Sale: Ethics \& Exploitation in the Human Body Trade by Wilkinson. ${ }^{2}$ 
quite strong arguments against them-for example, arguments to do with undesirable extensions of the cash nexus into parts of our lives hitherto untouched by it-but the arguments offered by Edwards et al are about exploitation, and they do not seem to work; and even if they did, they would produce an unresolved tension between the authors' desire to protect competent adults from (supposed) exploitation, and their overall claim that RECs should confine themselves to protecting the research subject's informed consent.

\section{A POSITIVE CONCLUSION}

We would like to conclude on a more positive note, by commenting on the moral authority and legitimacy of RECs. ${ }^{\text {iii }}$

This is something which Edwards et al find very troubling, and that is not surprising, given their tremendous insistence on the primacy of the autonomy of the individual subject. Once we abandon that insistence, however, it is reasonably clear where such legitimacy and authority come from. Legitimacy derives from the process of deliberation by the REC, as a lawfully established committee with representatives from the research and wider community, which has been given as its primary task, protecting potential research participants from unnecessary harm. Its authority comes from the fact that the REC consists of a diverse group of experts (including lay expertise), reaching agreement through discussion and consensus. This is not to say that any conclusion arrived at by a research ethics committee is infallible, but fallibility is the common condition of human institutions, and there are no more grounds to worry about the legitimacy and authority of RECs than of any other similarly constituted regulatory body.

In the process of deliberation a research ethics committee will as a matter of course attempt to balance autonomy, beneficence, and harm considerations in the context of the discussion of a particular research project. In our experience most RECs report that this is how they proceed. Such an approach can be justified by an appeal to different plausible positions in background moral theory-for example, a defeasibilist deontology appealing to prima facie duties which cannot be given a determinate rank order, or a pluralist consequentialism committed to a range of differing and sometimes incommensurable values. The authority and legitimacy necessary for making and imposing such judgments derives from this broadly based approach to ethical review. More specifically, given the fact that the primary aim of a REC is to protect participants in clinical research, a willingness to make paternalistic judgments where it is appropriate to do so strengthens that authority. Of course, neither the authority nor the legitimacy of REC decision making is unlimited, but that is cause for satisfaction rather than concern, since it shows that RECs are subject to the checks and balances which are appropriate for all institutions in a liberal democratic polity.

\section{Authors' affiliations}

E Garrard, A Dawson, Centre for Professional Ethics, Keele Hall, Keele University, Staffs, UK

\section{REFERENCES}

1 The Declaration of Helsinki, amended 2000, with clarification 2002. http:// www.wma.net/e/policy/b3.htm (accessed 9 Dec 2004).

2 Council for International Organisations of Medical Sciences. International ethical guidelines for biomedical research involving human subjects. http:// www.cioms.ch/frame_guidelines_nov_2002.htm (accessed 9 Dec 2004).

3 Edwards S, Kirchin S, Huxtable R. Research ethics committees and paternalism. J Med Ethics 2004;30:88-91.

4 Beauchamp T, Childress J. Principles of biomedical ethics [5th ed]. Oxford: Oxford University Press, 2001: especially ch 5.

5 Josefson D. Doctors volunteer to be guinea pigs for AIDS vaccine. BMJ 1997;315:831-6.

6 Snowdon C, Garcia J, Elbourne D. Making sense of randomisation; responses of parents of critically ill babies to random allocation of treatment in a clinical trial. Soc Sci Med 1997; 45:1337-55.

7 Featherstone K, Donovan JL. "Why don't they just tell me straight, why allocate it?" The struggle to make sense of participating in a randomised controlled trial. Soc Sci Med 2002;55:709-19.

8 Robinson E, Kerr C, Stevens A, et al. Lay conceptions of the ethical and scientific justifications for random allocation in clinical trials. Soc Sci Med 2004;58:811-24.

9 Tversky A, Kahneman D. The framing of decisions and the psychology of choice. Science 1981;211:453-8.

10 Tversky A, Kahneman D. Choices, values and frames. Am Psych 1984;39:341-50.

11 Holm S. Not just autonomy-the principles of American biomedical ethics. $J$ Med Ethics 1995;21:332-8.

12 Wilkinson S. Bodies for sale: ethics \& exploitation in the human body trade. London: Routledge, 2003: especially ch 2. 